\title{
Realismo grotesco e carnalidade: inspirações bakhtinianas em estudos de
}

\section{games}

\author{
Tomasz Z. Majkowski \\ Doutor; Jagiellonian University, Cracóvia, Polônia \\ tomasz.majkowski@uj.edu.pl \\ Tradução: Natan Kussler \\ Universidade Federal do Rio Grande do Sul, Porto Alegre, RS, Brasil \\ natan.kussler@ufrgs.br \\ Revisão de tradução: Laura Barros \\ Universidade Federal do Rio Grande do Sul Porto Alegre, RS, Brasil \\ laurabarros5@gmail.com
}

\section{Resumo}

O objetivo deste artigo é reformular a crítica dos retratos do corpo humano e das interações humanas básicas em jogos digitais tendo em conta a teoria do carnavalesco e do realismo grotesco de Mikhail Bakthtin. De acordo com o estudioso russo, a segunda é a convenção estética dominante da primeira, facilitando a representação da essência do carnaval (entendido como visão de mundo, não como festival). Meu argumento é que várias deformações grotescas do corpo em jogos de videogame mainstream e de orçamento alto, como protagonistas masculinos muito musculosos, mulheres hipersexualizadas e inimigos hediondos ou inumanos, assim como a estranha obsessão em produzir cenários fotorrealistas, se configuram firmemente dentro dessa estética. O mesmo se aplica ao corpo fragmentado, incompleto do protagonista em perspectiva de primeira pessoa. O imaginário é ainda mais reforçado pela maneira comum que games $A A A^{1}$ lidam com interação humana, pois tendem a reduzir qualquer contato a várias colisões de corpos, jogando qualquer outra convenção social - mesmo uma simples conversa - para fora do terreno do gameplay ou reduzindo-a drasticamente. A mais importante colisão desse tipo é, claro, o combate frequente de natureza violenta excessiva. As lutas conjuram importantes aspectos do carnavalesco: humilhação ritual e o desmantelamento de hierarquias - representadas pela clara estratificação de

\footnotetext{
${ }^{1}$ Nota do Tradutor: Jogos "triplo A" são aqueles que contam com grandes orçamentos para produção, distribuição e divulgação. Por esse motivo, o termo é também associado a projetos de maior porte das grandes empresas desenvolvedoras.
} 
antagonistas, variando em força e perigo que apresentam ao protagonista - reduzindo-as a sua carnalidade. Esse modo de interpretação abre mais perspectivas em consideração à questão da importância social de jogos de videogame violentos como possíveis veículos de expressão de oposição a ordens políticas e éticas estáticas.

\section{Palavras-chave}

Carnaval. Grotesco. Carnalidade. Violência em Games. Bakhtin.

\section{Introdução}

Middle-Earth: Shadow of Mordor (Monolith Productions, 2014) é um verdadeiro exemplo de brutalidade. Um solitário guardião de Gondor vaga pelo principal domínio do mal, eliminando dúzias de orcs maléficos. As cabeças cortadas dos seres de corpos de forma humana grotescamente deformados caem no chão como peras maduras. Isso vai contra o espírito da saga original de J. R. R. Tolkien, em que o personagem equivalente ao protagonista do jogo não sente alegria ao cortar cabeças de orcs. Ao invés disso, a justificativa vem da estética bruta do filme baseado em 0 Senhor dos Anéis. Graças, em parte, a essa conexão, isso não provocou desaprovação dos críticos, que majoritariamente foram firmes em seus elogios a Shadow of Mordor apesar das dúvidas que precederam ao lançamento. Isso não significa que o jogo ficou livre de críticas. Uma das avaliações negativas mais intrigantes foi a opinião de Zach Gage - um jornalista, autor de games e artista independente - expressado no website Polygon. Gage estava incomodado pelo fato de que o tutorial para se esgueirar, usado durante o curso do jogo para derrubar inimigos, envolvia o herói esgueirando-se até sua mulher para roubar um beijo. Ele é bem incisivo: "Designers não deveriam fazer beijar e assassinar parecer a mesma coisa." (GAGE, 2014), especialmente considerando as emoções que acompanham essas duas diferentes ações.

Esse caso anedótico ilustra três tópicos significativos na crítica dos games fora da academia. 0 primeiro é que matar é fundamentalmente diferente de outras atividades carnais (nesse caso, uma representação física de amor). 0 segundo é que críticos colocam que essa divisão pode levar a uma valorização negativa dos atos de violência em oposição ao valor positivo atribuído a outros tipos de atividade. E terceiro, como muitas das avaliações positivas do game demonstram, uma maneira diferente de descrever violência é relativamente rara: se não se atribui um valor negativo, ela se torna translúcida e 
indistinguível de uma aventura (MORAN, 2014; DUTKA, 2014). Combate, ao qual imagens brutais estão associadas, começa a ser descrito principalmente como um sistema de limpeza clínica (CAMERON, 2014).

O objetivo desse artigo é problematizar de forma diferente as imagens de violência e corpos caindo devido à violência em jogos digitais. Eu pretendo renunciar completamente ao tópico didático, e não me preocupar com a questão de se a saturação da violência em jogos digitais tem um efeito positivo ou negativo no jogador. Similarmente, a questão de problematizar a violência como medida de qualidade artística de um game (vista na crítica de títulos como Spec Ops: The Line ou This War of Mine) é apenas um contexto distante. 0 objetivo primário é tentar criar uma perspectiva teórica que esclareçam os três problemas ao mesmo tempo: a associação de games com imagens de destruição, o prazer derivado de ações brutais em games, e a identificação dos modos dominantes de apresentar corpos e interações carnais.

Isso não significa que eu vou ignorar produções interessantes e importantes que abordem seriamente a violência ou problematizam a cultura visual baseada na violência. Esses títulos, entretanto, são devidamente abordados em enfoques acadêmicos. Como resultado, eu estou mais intrigado pela posição que a brutalidade ocupa em títulos mainstream de alto orçamento, criados ostensivamente para entretenimento. Minha ideia é que os aspectos que vou discutir estão presentes em algum grau na maioria dos jogos digitais, embora nem todos estejam igualmente saturados com eles. É indiscutível que as perspectivas mais interessantes e brutalmente explícitas do corpo podem ser encontradas entre os maiores sucessos financeiros e os gêneros mais populares: games de tiro, ação e aventura, games sandbox, ou RPG, especialmente o subgênero hack\&slash.

\section{Imagens de corpos grotescos}

Apesar da tendência recente de imitar a estética de quadrinhos ou animações, o paradigma estético dominante da maioria dos games de gêneros mencionados anteriormente é uma versão popular do realismo (ABERCROMBIE; LASH; LONGHURST, 1996). Na crítica popular esse tipo de representação era, e às vezes ainda é, usado para julgar a qualidade artística do game convencional. Isso se manifesta no nível de apresentação estética, recriando locais com minúsculos detalhes e efeitos físicos meticulosamente simulados como gravidade, luz, fricção ou até mesmo o comportamento 
realístico do cabelo do personagem. Também se manifesta no nível de observações sociais básicas, como IAs, ou simulações de comportamento de multidões. Mesmo quando a estética se afasta do realismo, como é o caso da saga Borderlands (Gearbox Software, 2009-2015) e Fable (Lionhead Studios, 2004-2014), ou em games feitos para crianças, a qualidade da simulação da natureza é normalmente a mesma, também assegurada pelas regras da engine no qual o jogo é criado.

Entretanto, até mesmo as produções mais rigorosamente realistas introduzem uma diferença significativa entre as maneiras que apresentam objetos inanimados e personagens vivos. Os primeiros normalmente estão mais próximos do fotorrealismo e regidos por representações da física, assim como suas contrapartes no mundo real (exemplo: é desejável que um objeto de madeira seja quebrável). Os segundos - levemente deformados e regidos por regras arbitrárias ou convencionais. A representação mais visível dessa divisão é o sistema altamente convencional de infligir e receber lesões que - em situações extremas permite ao protagonista sobreviver múltiplos ferimentos causados por armas de fogo e recuperar a saúde total após alguns segundos atrás de uma barreira segura. Esse sistema substituiu o antigo, mas similarmente arbitrário modelo de recuperar saúde com o uso de kits de primeiros-socorros ou outros suprimentos médicos. Além dessa durabilidade aumentada, heróis e inimigos às vezes possuem outras qualidades que contradizem o realismo postulado: a habilidade de aderir a superfícies quase verticais, pular distâncias uniformes independente das circunstâncias, ou sua grande resistência ao dano causado por quedas. Esses são apenas alguns aspectos em um tipo de jogo que não se separa realmente do realismo. A saga Assassin's Creed (Ubisoft, 2007-2014), por exemplo, pretende construir detalhes históricos inéditos, mas permite modos de movimento que abandonam completamente quaisquer regras de anatomia humana.

Uma contradição similar pode ser encontrada na perspectiva estética. Corpos humanos em jogos digitais frequentemente aparecem de forma altamente fetichizada em dois níveis simultâneos. Primeiro, passa por várias deformações: os inimigos muitas vezes são apresentados como feios e mutilados enquanto os protagonistas são com frequência altamente sexualizados. Esse último aspecto foi, é claro, vastamente descrito, especialmente por críticas de games de orientação feminista (KENNEDY, 2002), (MACCALLUM-STEWART, 2014). Segundo, games mainstream, especialmente aqueles com combate pesado, divertem com exibições de danos, apresentando (às vezes em câmera lenta) os golpes que terminam a luta, como recompensa por uma boa performance. Exemplos disso vão desde arrancar 
cabeças e espinhas dorsais no primeiro Mortal Kombat (Midway Games, 1992), aos Raios-X exibindo o dano feito pelos tiros do herói em Sniper Elite (Rebellion Developments, 20052014).

O privilégio do corpo como a principal matéria estética vai ainda mais longe: os complexos criadores de personagens, específicos de RPGs ou The Sims, que permitem a customização da aparência do protagonista não estão atrelados aos similarmente complexos sistemas de escolha de comportamento ou personalidade. Mesmo a voz do protagonista não é tão meticulosamente modificada. Muitos games separam claramente os objetos capazes de movimentação e ação dos objetos decorativos, vinculando movimento à habilidade de agir violentamente sobre outros personagens no mundo do game. Isso frequentemente leva a uma clara divisão entre inimigos se movendo e aliados imóveis - assunto que já abordei em outro lugar (MAJKOWSKI, 2012). Finalmente, na maioria dos games dos gêneros discutidos, o corpo do protagonista organiza a experiência de jogo definindo a movimentação de câmera e tomando uma posição central na tela no caso de games com perspectiva em terceira pessoa. No caso de games de perspectiva em primeira pessoa, ela identifica a posição física do jogador na posição do corpo do personagem. Mesmo a visão isométrica, que permite o ajuste do ponto de vista ao ponto que o personagem central é invisível, assume o ponto de vista neutro, automático, em que o corpo toma posição no meio da tela.

Parece que a tendência descrita corta a estética padrão do game pela metade. Uma metade se concentra nos detalhes inanimados, não-humanos, que buscam imitar a realidade. A outra deforma o corpo humano de várias maneiras, atribuindo a ele algumas capacidades incríveis. Essa dualidade encontra concordância quando interpretada como um sintoma do realismo grotesco, prática estética descrita por Mikhail Bakhtin em Rabelais and his World. Bakhtin afirma que essa dualidade é o aspecto mais importante da cultura do riso (uma subcorrente cultural informal, antagonística à cultura oficial pomposa e solene), expressada em sátira, fenômenos carnavalescos e várias formas de excesso (BAKHTIN, 1999). Entre os aspectos estão a exposição e afirmação do corpo humano e da carnalidade através de um tipo específico de feiura. Isso inclui combinar o que não deveria ser combinado, apresentando momentos de humilhação, descrevendo excessos carnais eróticos e gástricos bem como mutilação e variadas deformações. 0 objetivo não é criar nojo pelo corpo, mas apresentá-lo como constantemente conectado ao mundo e a outros corpos, sempre despreparado, se tornando, dando à luz, morrendo, e sendo recriado. Ao mesmo tempo, o realismo grotesco não se separa da representação realista. Ao invés disso, assim como o 
movimento conectado à cultura oficial e definido como realismo clássico por Bakhtin (BAKHTIN, 1999), que evita a apresentação do tempo e sugere que o agora é eterno e constante, ele se concentra na natureza passageira tanto do corpo quanto da ordem social em que o corpo está presentemente posicionado.

Acredito que a deformação grotesca da imagem do corpo que ocorre em jogos digitais pode ser descrita nessa categoria. Primeiro, há a forte tendência de apresentar a imagem do protagonista principal como incompleto: o jogador pode influenciar e modificar a imagem mudando, por exemplo, a roupa. A importância desse recurso é indicada pelo fato de que opções de modificações adicionais são monetizadas e disponíveis como complementos pagos, ou como recompensa por um gameplay especialmente cuidadoso ou engajado. Tendências parecidas são encontradas nas regras quando os personagens passam por algum desenvolvimento. Normalmente é uma transformação de via única, levando o personagem à excelência, embora haja títulos nos quais o herói passa por uma degradação, como Jim Guthrie's Superbrothers: Sword and Sorcery (Capybara Games, 2011) ou Shadow of the Colossus (Team Ico, 2015). Em ambos os casos, é uma clara prova da presença do personagem principal no tempo, seu "tornar-se" gradual, oposto ao "ser" estático. Essa fluidez se manifesta principalmente no corpo do personagem, nos quais as regras descritas de desenvolvimento se aplicam: ele se torna mais forte, mais durável, ágil ou capacitado conforme o game prossegue. Esse desenvolvimento é mais frequentemente acompanhado por uma mudança na posição social, descrita no nível narrativo, do que por mudanças psicológicas normalmente encontradas na literatura, as quais Bakhtin também associa à cultura do riso (BAKHTIN, 1981).

Ainda por cima, a deformação dos corpos dos personagens normalmente ocorre de duas maneiras. No caso do protagonista e de personagens positivos, ela se manifesta em atributos associados à atratividade: músculos superdesenvolvidos no caso dos homens (o caso extremo é Marcus Phoenix em Gears of War [Epic Games, 2006]) e seios grotescamente largos e normalmente animados de forma irrealista no caso de mulheres - ou, em geral, representações intensificadas de características eróticas. 0 auge irônico dessa tendência é apresentado em Bayonetta (Platinum Games, 2009). Frequentemente as deformações tomam a forma de cicatrizes (especialmente faciais) e tatuagens, elementos constantes em criações de personagens em cRPGs. Tais imagens do corpo humano normalmente atraem críticas de perspectiva feminista. Elas parecem ocupar, no entanto, um lugar importante no realismo grotesco, que expõe o lado erótico e carnal da natureza humana, em oposição ao 
realismo "clássico", associado à arte oficial, erudita. Essa última estetiza o humano e o equipara à psique, tentando representar o ser humano como finalizado e eterno. 0 próprio Bakhtin descreveu dessa forma a polêmica interna da cultura do final da Idade Média, entre a cultura oficial, baseada no imaginário da Igreja e a não-oficial, popular e com descrições vulgares de carnalidade. Porém, em relação à perspectiva feminista, os argumentos se relacionam com as exigências por uma "forte protagonista feminina" cuja força seria uma qualidade da mente, identificada com independência, astúcia e coragem, e não do corpo (BAKHTIN, 1999). Embora seja obviamente problemático, isso se encaixa na convenção descrita cujo objetivo é derrubar o sistema estático de valores incorporados na cultura oficial, especialmente através de imagens inapropriadas, até mesmo blasfemas. Esse gesto em games é obviamente restrito devido à censura embasada no comércio. Essa é a razão, na minha opinião, para a falta de representações grotescas de nascimentos, defecações, nádegas expostas ou pênis desproporcionalmente grandes.

A alternativa para essa representação do protagonista, e para atribuir a ele a posição central da tela, é assumir a perspectiva em primeira pessoa, que cobre aspectos do corpo do protagonista. Às vezes a cobertura é dupla, como no caso de Crysis (Crytek, 2007) ou Halo (Bungie, 2001), onde o corpo físico do herói fica escondido debaixo de um traje espacial ou armadura. Eu vou, por ora, deixar de lado a dualidade das relações inerentes a esse modo de apresentação do corpo em relação à forma do jogador. Aqui eu quero apontar que mesmo nesses casos, o jogador tem acesso parcial à imagem de seu personagem.

Mãos ou pés podem ser vistos com frequência. 0 corpo não apenas passa por uma grotesca hiperbolização, mas também é fragmentado. A segmentação - dividindo o que é naturalmente inteiro e juntado de novo em combinações incomuns - está entre os elementos centrais do realismo grotesco (BAKHTIN, 1999) e é frequentemente usada na estética carnavalesca. 0 corpo segmentado da protagonista coloca ela (e com ela, o jogador), no papel de rei carnavalesco, o governante humilhado dos excessos sagrados (BAKHTIN, 1999), embora a humilhação aqui esteja associada mais à posição antagonística dos outros atores do mundo e às múltiplas, algumas vezes cumpridas, ameaças de morte.

A segunda convenção está associada à monstrualização dos inimigos ou a sua grotesca desumanização. Essa tendência é especialmente visível em games que usam a estética fantástica, onde há racionalização ao introduzir outras raças de humanoides. Isso não muda o fato de que inimigos são muitas vezes aliados mutacionados: isso acontece na saga Mass Effect (Bioware, 2007-2012), ou em qualquer game com a temática zumbi ou suas 
modificações, como os híbridos cogumelo-humanos de The Last of Us (Naughty Dog, 2014). A monstrualização tem seu lugar no campo audiovisual, mas nesse caso parece ter um aspecto adicional: introduzindo a categoria estética que Bakhtin chama de "monstro risível". Um ser que é deformado grotescamente, monstruoso, causando simultaneamente medo, riso e piedade. É normalmente uma metáfora para a figura da ordem metafísica oficial. Depois de uma grotesca transformação, aqueles temidos na vida real se tornam hediondos e simultaneamente temíveis e patéticos. Um exemplo de tal personagem é o rei carnavalesco, escolhido entre os participantes mais feios e mais deformados do festival, ou as figuras grotescamente fantasiadas do Ano Novo. Dessa forma, a natureza desamparada e passageira do sistema é exposta, diminuindo a distância absoluta entre as regras e os sujeitos. A humilhação ritual (e, às vezes, destruição) desse tipo de figura é um ato de libertação, restaurando a familiaridade nas relações entre as pessoas (BAKHTIN, 1999).

Analogias entre a figura do monstro risível e o antagonista deformado de um game são visíveis não apenas nas regras de representação, mas também podem ser encontradas nas partes diegéticas do game. As relações entre os monstros risíveis com o poder são expressadas não apenas em seus elevados números, mas também em hierarquias internas que não estão tão claramente presentes nos heróis positivos. As pragmáticas do gameplay se associam aqui às semânticas do carnaval: o herói solitário, embora representante de um interesse coletivo de grupo, se opõe a um sistema de inimigos em que há níveis claramente distinguíveis de ameaça, onde o mais alto é às vezes chamado, de forma bem apropriada, de "chefe". Durante o curso da luta, o herói sobe pela hierarquia, começando com inimigos subservientes que representam pouca ameaça e terminando com os inimigos mais poderosos, normalmente dominantes na ordem social dos inimigos e distinguíveis pelo tamanho aumentado. Como resultado, o herói cumpre sua missão carnavalesca em desconstruir a ordem hierárquica, expondo o defeito mais importante: a diferença aparente de qualidade entre dois pontos de uma escala social é, na verdade, uma diferença de quantidade. Todos os membros da ordem social hostil cumprem as mesmas regras e entregam-se à mesma linguagem: violência. Essa desconstrução reconstitui o mundo, na qual a regra básica do carnaval - a igualdade e a familiaridade das relações humanas - é restaurada.

Naturalmente, essa conclusão radical é suavizada, normalmente ao introduzir uma hierarquia nos heróis positivos. Ela tem muito menos consequência, entretanto, e é usualmente introduzida no nível narrativo, fazendo do protagonista um soldado, um capitão, 
ou um policial dentro da história. Uma hierarquia desse tipo só tem um efeito marginal no gameplay, que é durante as confrontações em que o herói age ou sozinho ou como líder de um pequeno grupo (isso também é verdadeiro no caso de múltiplos heróis, como em jogos de estratégia). Se eles respondem ao poder, é mais em termos de controle do jogador e das capacidades e objetivos do game do que em termos de hierarquia de comando dentro da diegese.

A relação entre o jogador e o protagonista necessita de mais problematização. Há uma razão pela qual eu vim evitando o termo "avatar", adotado para descrever o personagem pelo qual o jogador "se transporta" para o espaço do game. 0 movimento que o jogador executa para interagir com o jogo, especialmente no caso de games single player, parece ser baseado em um reconhecimento ao menos parcial da autonomia do protagonista, de maneira que ele pode se tornar o personagem central da narrativa presente no game. De maneira parecida, o jogador reconhece o corpo do protagonista como diferente do dele próprio, ao mesmo tempo em que projeta suas próprias emoções da maneira descrita por Bakhtin em Author and Hero in Aesthetic Activity (BAKHTIN, 1990). Games tentam reduzir essa distinção através de duas ferramentas básicas. A primeira envolve uma característica espacial que busca identificar a posição do espaço ocupado pelo protagonista com o lugar onde o jogador está - isso acontece no caso da perspectiva de primeira pessoa. A segunda está associada ao tempo e depende da impressão que as ações do jogador e as do protagonista são simultâneas: isso é, puxar o gatilho no controle acontece ao mesmo tempo em que o herói atira com a arma de fogo. Essa simultaneidade, que eu quero destacar, é realizado no nível de engajamento do corpo. Quando o game emprega ferramentas similares a narrativas literárias ou de filmes para introduzir o enredo, a impressão de simultaneidade desaparece ou enfraquece. Especialmente tendo em conta que muitos games aumentam o controle do jogador sobre o fluxo do tempo durante tais momentos, permitindo que eles pulem a sequência animada. Relações físicas entre o jogador e o protagonista são ambivalentes e ainda mais complicadas pelo fato de que as ações físicas do protagonista são traduzidas para as ações físicas do jogador, como destacam Gregersen e Gorodal (GREGERSEN E GRODAL, 2008) - elas têm uma equivalência em um movimento mais ou menos natural do controle. Em casos extremos, quando controles de movimento são empregados, a similaridade do movimento pode ser bem avançada. Ao mesmo tempo, acredito, o jogador permanece consciente que o herói é removido de certa forma ao reagir a certos movimentos e gestos, diferente de uma marionete de cordas, subordinado a cada 
puxada de um fio. Não quero analisar o sistema inteiro em toda a sua complexidade, mas simplesmente salientar que essa relação aumenta a natureza grotesca da representação, conectando o corpo do protagonista com o corpo físico do jogador de uma maneira característica à figura do sistema estético apresentado: um ser de dois corpos (BAKHTIN, 1999), possuindo características autônomas do herói e dependendo das competências manuais do jogador. 0 movimento do protagonista e o movimento do jogador, seguindo o mesmo objetivo e realizados no mesmo momento, permanecem conectados, mas, simultaneamente, separados e passíveis de distinção.

\section{Interações do corpo grotesco}

Nos aspectos tradicionais da cultura do riso, o corpo carnavalesco, grotesco, é um corpo comunal. Ele participa da comunidade familiar comum e carnal de seres agindo sob leis análogas às da natureza em detrimento das estratificações culturais (BAKHTIN, 1999). Esse tópico é mais difícil de traçar em jogos digitais, e pode parecer que prestar atenção especial ao protagonista, o único ligado ao corpo do jogador e, portanto, qualitativamente diferente de outros personagens do jogo, pode invalidar as conclusões anteriores. Esse tópico é destacado por Rune Klevjer (KLEVJER, 2014), que argumenta que diferenças qualitativas negam qualquer possibilidade posterior de uma interpretação Bakhtiniana.

Embora eu concorde com a identificação do problema, eu acredito que é importante notar dois contextos. Primeiro, o ato singular de jogar traz à tona uma transformação do jogador e do protagonista em um ser de dois corpos. Tal transformação singular pode ser transferida para a comunidade de gamers como um todo. Em múltiplas cópias do jogo, jogadas por diferentes jogadores, o mesmo protagonista, no mesmo lugar da narrativa e nas regras do game, se combina com diferentes jogadores (e seus corpos), criando numerosos seres de dois corpos. Isso é, entretanto, um tópico que requer uma análise separada. Segundo, e mais importante para essa análise, é a distinção de games de outras formas de cultura do riso, especialmente do fenômeno social do carnaval, a própria forma que Bakhtin descreve usando a noção de corpo comunal (BAKHTIN, 1999). Games parecem estar mais perto de formas narrativas que, como Bakhtin escreve, são mais carnavalescas que o próprio carnaval. Portanto, alguns fenômenos, claramente observados em festivais de rua, são problematizados ou apresentados como metáforas. Os mesmos processos acontecem no romance, que é o assunto principal de interesse de Bakhtin. No nível de narrativa, o corpo 
coletivo encontra seu equivalente na polifonia e na heteroglossia do romance, que está na igualdade de vários pontos de vista e linguagens socialmente enraizadas que não cedem ao regime do discurso ideológico e da hierarquia oficial (BAKHTIN, 1981). Em jogos digitais, esse tema é visível tanto no nível da narrativa, de onde vem o prestígio de várias sequências de "escolhas morais" que mudam os enredos, quanto no nível de construção. Ali, o game é um conglomerado de maneiras diferentes de descrever o mundo: narrativo, sistêmico (expressado nas mecânicas do game), cinemático, etc. Isso é acompanhado não apenas por um interesse na carnalidade grotesca, outra narrativa equivalente às práticas carnavalescas (descritas anteriormente), mas também por regras de interação entre personagens, orientadas ao redor de contato físico e estabelecimento de uma comunidade.

Duas importantes soluções para o dilema da falta de um corpo comunal estão associadas a esse último aspecto. A primeira é o papel negativo da hierarquia e a representação de seu desmantelamento como a tarefa central do herói, ambas no nível do gameplay, através da eliminação de inimigos cada vez mais poderosos, que eu descrevi anteriormente. E no nível da narrativa, como é o caso das sagas Assassin's Creed e Grand Theft Auto (Rockstar, 1997-2014), ou o anteriormente mencionado Middle Earth: Shadow of Mordor: nesses games, o herói é incumbido de destruir hierarquias opressoras (templários, sindicatos do crime, servos de Sauron) para, no lugar, criar uma sociedade de laços comuns.

A segunda é a eliminação da vida privada em games ao introduzir personagens que não são inimigos do protagonista. Multidões anônimas das sagas Assassin's Creed, Saint's Row (Volition, 2006-2015) ou Mass Effect existem apenas em espaço público, nas ruas e praças, esperando para que o herói interaja com elas. Isso pode ter um efeito triplo: na primeira das sagas mencionadas acima, o herói pode desaparecer na multidão, reduzindo sua singularidade e temporariamente se tornando parte de um corpo coletivo. Esse corpo coletivo é regido pelas mesmas regras, e a variedade de $\mathrm{NPCs}^{2}$ é ilusória, embora reflita a característica carnavalesca de misturar pessoas de diferentes origens e estratos sociais. No segundo caso, a multidão vira presa da brutalidade do protagonista e serve como objeto de eliminações visualmente deslumbrantes e uma escalada da violência. 0 terceiro caso parece ser o mais sintomático: o comandante Shepard vaga pela Cidadela espacial, entre multidões discutindo publicamente os assuntos mais íntimos, incluindo problemas de saúde e a vida sexual. 0 herói com frequência pode se juntar à conversa e se tornar parte da vida de

\footnotetext{
${ }^{2}$ NPC é a sigla para Non-Playable Character, ou Personagem Não-Jogável. Tratam-se, portanto, dos personagens que o jogador não pode controlar.
} 
eventos que a cultura Ocidental considera privada e elimina da esfera pública (BAKHTIN, 1981). A narrativa torna Shepard um confidente e solucionador de dilemas pessoais. É provavelmente o modelo mais comumente encontrado de representações de contatos familiares com o corpo comunal: o protagonista se torna a pessoa que carrega os problemas de toda a comunidade, devotado a eles sem hesitação ou protesto. Os problemas que eles solucionam raramente os tocam pessoalmente. Os problemas ou afetam toda a comunidade (quando ela precisa ser salva) ou são resultado de interação com a comunidade.

Ainda assim, o combate permanece como a maneira básica de interação entre corpos apresentadas no game - alguns games sequer introduzem outras formas de interação, e outros restringem-nas consideravelmente (assumindo que tocar os outros é possível apenas em cutscenes $^{3}$, sem a influência do jogador). Tais representações de contato humano se encaixam ordenadamente na poética do realismo grotesco: é destacado pelo próprio Bakhtin, quando ele descreve o combate como um dos possíveis modelos de degradação, próximo à feiura curiosa, humilhação verbal e exposição de excrementos (BAKHTIN, 1999). Um tópico similar é levantado por John Fiske quando ele destaca o aspecto carnavalesco de lutas de wrestling (FISKE, 1989). Degradação é adjacente ao esquartejamento, que serve não apenas como humilhação carnavalesca, e se enquadra na categoria mais ampla de refazer o mundo de cabeça para baixo, mas também serve como afirmação da anatomia, trazendo atenção aos elementos do corpo humano que normalmente ficam escondidos do olho humano. Essa inabilidade de perceber entranhas, como Bakhtin argumenta, perpetua o mito da estabilidade, intocabilidade e a beleza do corpo humano, característico do realismo clássico cujo grotesco se opõe. Degradações grotescas parecidas às vezes podem ser encontradas em imagens de combate em games: movimentos de finalização elaborados, cabeças explodindo ao impacto, decapitações, pilhas de corpos inimigos ou uma generosa quantidade de sangue manchando as roupas e corpo do protagonista.

Porém a desconstrução de monstros risíveis e a humilhação do corpo não são as únicas alegorias ligadas aos visuais de combate brutal em jogos digitais. Eu sequer acho que elas são as mais importantes. Mais significante parece ser o fato de que o combate é a única situação em que o corpo do protagonista/jogador vai em contato direto com outros corpos e entrelaça com eles, ao mesmo tempo removendo e reforçando a fronteira entre eles. Elementos do herói/jogador entram no inimigo (especialmente em games com balística) e os golpes do inimigo entram no corpo do protagonista. Ao mesmo tempo, essas trocas

${ }^{3}$ Cutscenes são sequências durante as quais o jogador não pode interagir com o jogo. 
significam uma mudança no status, perda de poder, movimento em direção à submissão, e demandam uma distinção clara de quais corpos recebem e quais iniciam o contato. Novamente, Rune Klevjer vê nessa alegoria um afastamento dos princípios do realismo grotesco (KREVJER, 2014). No entanto o conflito físico, domínio de um dos combatentes, morte em combates singulares e em grandes números, todos se encaixam facilmente na estética analisada por Bakhtin. 0 próprio estudioso russo analisou exemplos tirados tanto da literatura carnavalesca, como afogamentos em massa de inimigos e pessoas inocentes em torrentes de urina de Pantagruel (BAKHTIN, 1999), e atividade de carnaval, como o relatório de uma luta de facas encenada durante o carnaval romano (BAKHTIN, 1999). Um significado similar pode ser derivado das lutas de wrestling, como interpretado por Fiske. Dessa forma, a velha vida dá lugar à nova, como na poética grotesca, morrendo e nascendo como elementos da mesma existência humana em seu aspecto temporal - vêm de uma mesma imagem ambivalente, uma metáfora na qual a imagem é de uma mulher velha grávida, ou de uma dando à luz (BAKHTIN, 1999).

Esse tipo de ambivalência acompanha o combate brutal em games. 0 corpo do herói/jogador é envolvido pelo eterno círculo de morrer e renascer, nunca sendo completamente destruído - esse tema, no exemplo de GTA IV, foi analisado por Mark Butler (BUTLER, 2010). Uma regra similar rege os corpos dos antagonistas nos games onde inimigos reaparecem. Ainda mais, se o herói/jogador derrota um inimigo, o corpo é frequentemente é impregnado e sua morte dá nascimento a itens não apenas não presentes antes no mundo, mas agora disponíveis para consumo do protagonista. Eles tomam a forma de vida adicional, pontos de experiência e, acima de tudo, pilhagem, cuja aparência pode ser tão grotesca e não-natural que muitos games abertamente zombam da mecânica, embora não a questionem. Lado a lado com o mecanismo de esquartejamento e degradação aparece a metáfora de copulação, impregnação, e nascimento, intimamente associada e problematizada pelo jogo como forma de esforço. A metáfora do masculino não está completamente ausente na cultura ocidental, na qual o ato sexual é por vezes descrito como "luta de amor". A alegoria é apresentada de maneira mais discreta devido a restrições sociais, mas é um resultado necessário (e provavelmente inconsciente) de empregar uma realidade estética grotesca, na qual a morte é indissociavelmente ligada ao nascimento e à acumulação de posses. Para descrever esse fenômeno, Bakhtin usa a metáfora de uma semente que é empurrada na lama (e, portanto, humilhada e morta) para trazer um broto. 
Ao mesmo tempo, o ato de pilhagem, que está devorando os restos dos inimigos mortos, abre espaço para outra alegoria importante para essa estética: consumo ilimitado. 0 centro da vida grotesca não é a mente, mas o estômago, de onde vem o riso e que demanda sustento abundante. A boca aberta, distorcendo a fronteira entre o corpo e o mundo, a preparação para devorar novos elementos desse mundo, a fome insaciável e o prazer de comer são imagens carnavalescas constantes. Uma fome insaciável similar é um constante elemento do gameplay. 0 herói se torna mais poderoso ao devorar o que sobra dos inimigos destruídos: itens cada vez mais poderosos, pontos e dinheiro. Às vezes, especialmente em games de plataforma, eles também devoram alguns elementos do mundo: orbes de energia pairando no ar, moedas giratórias e outros itens que ajudam a medir o progresso. Uma ilustração particularmente espetacular dessa tendência é a mecânica usada em Fable 2 (Lionhead Studios, 2008) (de outra forma também saturada com imagens carnavalescas), onde os inimigos se transformam em orbes coloridos e o jogador deliberadamente se alimenta deles. Dessa maneira o que é externo entra no corpo do protagonista, mudando-o e fortalecendo-o.

O apetite do herói/jogador é insaciável. É difícil fazer com que o jogador pare de acumular itens, mesmo aqueles que não serão úteis. Essa tendência é restringida por games que introduzem vários limites de itens que podem ser carregados de uma vez. 0 excesso então deve ser removido do corpo do protagonista, introduzindo a terceira categoria chave do realismo grotesco: defecação. Embora a imagem de fezes e urina seja ainda mais rara nos games que cenas de copulação, acredito que nos atos de reduzir o excesso de itens no inventário há uma metáfora clara, fortalecida com a experiência no game. Simplesmente retornar os itens em formas inalteradas, jogando-os fora (vomitando) não é satisfatório. A satisfação vem apenas de remodelar o lixo inútil em alguma outra forma: vendendo-o, desmantelando-o para obter peças sobressalentes, transmutando-o em uma matéria diferente. Se assumirmos então que a obsessiva coleção de itens, mesmo os inúteis, é uma metáfora para o apetite carnavalesco insaciável, o ato satisfatório de transmutá-los em uma substância diferente é uma metáfora para digestão e defecação. 0 estômago vazio está instantaneamente pronto para mais comida.

Os laços entre combate brutal, erotismo, consumo e defecação fazem parte de um círculo de gameplay na maioria dos games mainstream modernos. Disso origina-se a equivalência entre beijar e matar em Shadow of Mordor que tanto irritou Zach Cage, e que 
parece para mim ser um comentário preciso e humorado de fenômenos centrais mais amplos em games modernos.

\section{Consequências do corpo grotesco}

A dominância da estética do realismo grotesco parece ser uma consequência natural da relação entre games e a cultura do riso: seu caráter divertido, porém ultrajante, e as várias tensões temporais colocadas no processo de gameplay (que costumavam ser de grande interesse para acadêmicos (JUUL, 2004). Essa convenção nos permite lidar com a dificuldade de comparar consequências de modelos dominantes de gameplay, de não perguntar a razão das habilidades sobrenaturais dos personagens, não refletir sobre suas vidas privadas e emoções, não questionar a habilidade tanto do protagonista quanto dos inimigos de renascer constantemente. Imagens ambivalentes, estranhas, monstruosas, contribuem para uma proposta de estética coerente que não ofende com a falta de coerência, mas com sua maneira de criticar a ideologia dominante. Em outras palavras, faz a experiência de jogar games intelectualmente e emocionalmente aceitável, até mesmo satisfatória.

As razões para essa satisfação e suas consequências precisam ser explicadas. 0 prazer de jogar o game, a aproximação eufórica à matança sem consequência e as cenas de violência, todas as quais causam preocupações em acadêmicos, podem ser descritas em termos de riso carnavalesco e entusiasmo. Essas sequências profundamente inadequadas apresentam uma alternativa à narrativa oficial higienizada, cautelosa com violência em geral e emoções extremas - a narrativa que apela para conflitos moderados e se recusa a fazer de alguém um monstro ou inimigo. Parece também conectado ao desejo que Bakhtin fala: fundir-se na comunidade familiar, se entregando aos prazeres carnais, sem ser restringido por regras ou coexistência social, permite renovar o contrato entre a própria fisicalidade de alguém e o aspecto material da existência. Nesse contexto, games trabalham em paralelo com o carnavalesco, o excesso controlado e temporário que nos permite escapar brevemente do mundo da ideologia e ganhar novamente a energia necessária para então nos juntarmos outra vez àquela realidade.

Daí vem a suspeita e desgosto de fãs de games, que operam firmemente dentro do realismo grotesco, com as tentativas de usar games como ferramentas para educação ideológica. Demandas por sensibilidade, empatia, feminismo e consideração de políticas de 
representação hoje em dia são parte da narrativa oficial e, assim, são referência imediata para o poder paródico do imaginário grotesco. Como resultado, elas não podem ser integradas nas convenções estéticas familiares aos gamers. Elas podem apenas serem zombadas quando são usadas. Essa questão, junto com a marginalização da significação da violência e da destruição na forma de games modernos, me parecem a origem de tensões atuais no campo de críticas não-acadêmicas e das comunidades de fãs. Como resultado, acredito que são necessárias uma atenção maior e uma análise mais profunda do que essa modesta tentativa.

\section{Referências}

ABERCROMBIE, N.; LASH, S.; LONGHURST, B.. Popular representations: Recasting Realism. In: LASH, S.; FRIEDMAN, J. (Ed.). Modernity and Identity. Oxford: Blackwell, 1996.

BAKHTIN, M. A cultura popular na Idade Média e no Renascimento - o contexto de François Rabelais. São Paulo: Hucitec, 1999.

BAKHTIN, M. Discourse in the Novel. In: BAKHTIN, M.. The Dialogic Imagination: Four Essays. Austin: University Of Texas, 1981.

BAKHTIN, M. Forms of Time and Chronotope in the Novel. In: BAKHTIN, M. The Dialogic Imagination: Four Essays. Austin: University Of Texas, 1981.

BAKHTIN, M. Author and Hero in Aesthetic Activity. In: BAKHTIN, M.. Art and Answerability. Austin: University Of Texas, 1990.

BUTLER, M. On Reality and Simulation in an Extra-Moral Sense. In: GÜNZEL, S.; LIEBE, M.; MERSCH, D. (Ed.). Logic and Structure of the Computer Game. Postdam: Postdam University, 2010. p. 212-231.

CAMERON, P. Middle-Earth: Shadow of Mordor review. 2014.

DUTKA, B. Middle Earth: Shadow of Mordor Review. 2014.

FISKE, J. Understanding Popular Culture. [s.l]: Routledge, 1989.

GAGE, Z. Kissing vs. killing: How Shadow of Mordor fails at explaining the difference. 2014.

GREGERSEN, A.; GRODAL, T.. Embodiment and Interface. In: PERRON, B.; WOLLF, M.

(Ed.). The video game theory reader 2. New York: Routledge, 2008. p. 65-83.

JUUL, J. Introduction to Game Time. In: WARDRIP-FRUIN, N.; HARRIGAN, P. (Ed.). First

Person: New Media as Story, Performance, and Game. Cambridge: Mit, 2004. p. 131-142. 
KENNEDY, H. W. Lara Croft: Feminist Icon or Cyberbimbo?: On the Limits of Textual Analysis. The International Journal of Computer Game Research, [s.l], v. 2, n. 2, dez. 2002.

KLEVJER, R. Dancing with the Modern Grotesque: War, work, play and ritual in the runand-gun First Person Shooter. 2014.

MACCALLUM-STEWART, E. “Take That, Bitches!”: Refiguring Lara Croft in Feminist Game Narratives. The International Journal of Computer Game Research, [s.l], v. 14, n. 2, dez. 2014.

MAKJOWSKI, T. Z. Złote Runo: Gra wideo jako doświadczenie interpretacyjne. In: PITRUS, A.. Olbrzym w cieniu. Kraków: Wydawnictwo Uniwersytetu Jagiellońskiego, 2012. p. 177190.

MORAN, C. Middle-earth: Shadow of Mordor review: a glorious knockout punch. 2014.

\section{Referências Ludográficas}

Bioware, Mass Effect (series). Electronic Arts, 2007-2012.

Bungie. Halo. Microsoft Studios, 2001.

Capybara Games. Jim Guthrie’s Superbrothers: Sword and Sorcery, 2011.

Crytek. Crysis. Electronic Arts, 2007.

Epic Games. Gears of War. Microsoft Studios, 2006.

Gearbox Software. Borderlands (series). 2K Games., 2009-2015.

Lionhead Studios. Fable II. Microsoft Games, 2008.

Lonhead Studios. Fable (series). Microsoft Games, 2004-2014.

Midway Games. Mortal Kombat, 1992.

Monolith Productions. Middle-earth: Shadow of Mordor. Warner Bros.

Interactive Entertainment, 2014.

Naughty Dog. Last of Us. Sony Computer Entertainment, 2014.

Platinum Games. Bayonetta. Sega, 2009.

Rebellion Developments. Sniper Elite (series). MC2 France, 2005-2014.

Rockstar. Grand Theft Auto (series). Rockstar Games, 1997-2014. 
Team Ico. Shadow of the Colossus. Sony Computer Entertainment, 2005.

Ubisoft. Assassin's Creed (series). Ubisoft, 2007-2014.

Volition. Saint's Row (series). THQ; Deep Silver, 2006-2015.

\title{
Grotesque realism and carnality: Bahktinian inspirations in video game
}

\begin{abstract}
The aim of this paper is to re-frame criticism of video-game portrayal of the human body and basic human interactions in light of Mikhail Bakhtin's theory of carnivalesque and grotesque realism. It argues that various grotesque deformations of bodies in mainstream, high-budget video games fall into a bakhtinian aesthetic of carnivalesque and carnality. It reinforces that especially AAA games utilize this aesthetic through the representation of carnavalesque aspects, suchs as excessive violence, ritual humilitation and the dismantling of hierarchies, reducing or eliminating other social conventions from the realm of gameplay. It concludes that this mode of interpretation opens up further perspectives with regard to inquiry into the social importance of violent video games as possible vehicles for the expression of opposition to static ethical and political orders.
\end{abstract}

\section{Keywords}

Carnival. Grotesque. Carnality. Game violence. Bakhtin. 